\title{
A pesquisa em educação física e mídia nas ciências do esporte: um possível estadoatual da arte
}

\author{
Giovani de Lorenzi Pires*
}

\begin{abstract}
Resumo: a partir de algumas reflexões preliminares sobre as relações entre a cultura contemporânea, os meios de comunicação de massa e o campo da Educação Física, é formulado uma breve síntese classificatória dos estudos nesta área de interface, apresentados no âmbito do GTT Esporte e Mídia do Colégio Brasileiro de Ciências do Esporte (1997-2001), como ilustração de um possível "estado atual da arte".
\end{abstract}

Palavras-chave: Educação Física, Esporte, Mídia.

A demissão do jornalista da rede de televisão NBC, Peter Arnett, ${ }^{1}$ motivada por suas críticas à estratégia militar das forças de coalizão que invadiram o Iraque, serve como exemplo ilustrativo da complicada e pouco ética relação da mídia com o poder instituído.

Deste mesmo contexto, pode ser destacada uma série de fatos, como a determinação do governo Bush para que as TVs norte-americanas não apresentassem cenas de seus soldados feitos prisioneiros pelas milícias iraquianas ou a proibição de que os mariners do porta-aviões Ark Royal acompanhassem a programação da rede londrina BBC, considerada "pró-Iraque". Assim como a autêntica guerra de (des)informações veiculadas pelas diferentes emissoras que transmitem desde o Golfo - que incluiu a criação de uma emissora de TV aerotransportada, com a qual os norte-americanos transmitiam mensagens em árabe ao povo iraquiano - e o ataque (não suficientemente explicado) da artilharia norte-americana ao hotel Palestine, não por acaso onde

\footnotetext{
* Professor Adjunto do Departamento de Educação Física do Centro de Desportos/ UFSC, integrante do Núcleo de Estudos Pedagógicos da Educação Física - NEPEF/ UFSC. Ex-coordenador do GTT Esporte e Mídia do Colégio Brasileiro de Ciências do Esporte. Contatos: giovanipires@cds.ufsc.br

10 jornalista Peter Arnett tornou-se mundialmente conhecido como o principal correspondente da rede CNN, com a cobertura exclusiva da Guerra do Golfo, em 1991.
}

Movimento, Porto Alegre, v. 9, n. 1, p. 09-22, janeiro/abril de 2003 
estavam instaladas as redes televisivas árabes, inclusive a independente Al Jazeera, e que resultou na morte de cinco jornalistas.

$\mathrm{Ou}$ ainda a grande novidade entre as armas usadas pelos EUA no primeiro momento da invasão, que foi o dispositivo eletromagnético utilizado para "desnortear" (impossível resistir ao trocadilho!) os sistemas de comunicação iraquianos e dificultar a reação e a eficácia das suas baterias antimísseis.

Todos estes exemplos, recolhidos no interior desta situação limítrofe entre o processo civilizatório e a barbárie, que é a guerra, servem também para evidenciar uma vez mais a importância que os meios de comunicação de massa vêm crescentemente assumindo na sociedade contemporânea como o principal produtor/veiculador de sentidos que são culturalmente compartilhados, desde a apropriação social mais ou menos homogênea do discurso midiático. Importância essa que, reconheça-se, não está livre de grandes equívocos, notadamente os decorrentes das leituras dicotômicas e maniqueístas que caracterizam o apressamento/barateamento das análises: ora os meios de comunicação são apresentados como essencialmente "do bem", mesmo admitindo-se alguns "desvios", ora como algo irremediavelmente "do mal", concedendo-se apenas a possibilidade de "resistências" a eles.

Não é do escopo deste texto (nem cremos que seja possível fazê-lo em qualquer outro momento) elucidar toda a polêmica criada e alimentada na sociedade contemporânea, a respeito das relações (e do tipo de) que a mídia assume com um conjunto de interesses em que se articulam política, ideologia, mercado, cultura, etc., e as suas influências sobre o cotidiano social e individual. Nossa intenção se limita a traçar um pequeno quadro contextual didático que expresse, tanto quanto possível, o "estado atual da arte" da pesquisa na área da Educação Física/Ciências do Esporte (EF/CE) referente ao campo comunicacional e midiático. Todavia, é impossível prosseguirmos na empreitada se não identificarmos, como pressupostos: i) o reconhecimento de que nosso campo encontra-se atravessado tanto pela linguagem quanto pelos significados produzidos/veiculados pelos meios de comunicação de massa para os conhecimentos que caracterizam a área e ii) a necessidade, ainda bastante superior ao que, de fato, já se conseguiu efetivar, de que estas linguagens e sentidos tecnologicamente mediados sejam tematizados nas nossas investigações e estudos, a fim de que possamos vir a

Movimento Porto Alegre, v. 9, n. 1, p. 09-22, janeiro/abril de 2003 
estabelecer relações mais autônomas e emancipadas em relação à mídia e ao seu discurso. ${ }^{2}$

Os estudos sobre mídia estão presentes desde a década de 20, surgidos a partir da preocupação com os efeitos da publicidade, seja para entender como aperfeiçoá-los, seja para tentar criar mecanismos sociais de defesa a eles (Wolf, 2001). Houve, a partir daí, um grande número de desdobramentos e superações que constituem novas tendências teórico-metodológicas para análise da mídia. Embora a ainda incipiente área de estudos midiáticos no interior da EF/CE não seja subsidiária direta de tais tendências, consideramos importante apresentá-las, em forma de síntese, para que se possa compreender por onde têm passado as preocupações daquele campo, como indicativo para o entendimento do que vem-se fazendo em nosso próprio campo.

\section{Teorias da Comunicação: pressupostos atuais dos estudos sobre a mídia ${ }^{3}$}

Para nos situarmos no mapa conceitual-metodológico dos estudos sobre a mídia, apresentamos, então, de forma sucinta algumas das principais teorias da comunicação com base em elaborações procedidas por autores do campo sociocultural e midiático.

A primeira delas tem como referência a classificação organizada por Mauro Wolf (2001), que apresenta um conjunto de tendências de estudos, que podem ser assim apresentados:

F correntes funcionalistas: incorporam teorias anteriores como os modelos de massa e os estudos empíricos em geral, que buscavam conhecer os efeitos hipodérmicos dos meios de comunicação. Ao tentar explicitar as funções exercidas pelos mass media na sociedade, dirigem sua atenção não mais para fatos específicos/isolados, mas para a presença cotidiana dos meios no sistema

\footnotetext{
2 Discurso midiático é apresentado por Sodré (citado por Pires, 2002) como um caminho simbólico que serve para guiar as visões de mundo e as perspectivas de interação social dos diferentes grupos alcançados pela ação anunciativa. $\mathrm{O}$ atual discurso midiático se caracteriza pelo apagamento das linhas limítrofes entre informação, entretenimento e publicidade, do que resulta um certo embaralhamento (cfe. Feres Neto, 2001) entre estas funções sociais da mídia.

3 Esta síntese foi produzida inicialmente para o verbete sobre mídia do projeto de Dicionário Crítico da Educação Física, em elaboração pelo professor Paulo E. Fensterseifer, da UNIJUÍ.
}

Movimento, Porto Alegre, v. 9, n. 1, p. 09-22, janeiro/abril de 2003 
social, concebido como um organismo em razoável estabilidade, no qual todas as suas instituições (os media inclusive) encontram-se integradas;

F teorias críticas: com inspiração no pensamento marxiano e na teoria social crítica da Escola de Frankfurt, têm as reflexões sobre a Indústria Cultural como conceito-âncora. Pressupõem que qualquer estudo interessado em elaborar crítica às influências sociais e mesmo subjetivas dos meios de comunicação de massa precisam ter como cenário de referência a estrutura desigual e iníqua da sociedade capitalista;

F teorias culturalistas: têm origem nos estudos culturais franceses e investigam a contribuição da mídia na constituição da cultura de massa, compreendida como uma nova forma de organização da sociedade, envolvendo práticas, significados e valores culturalmente compartilhados;

F vertentes comunicacionais e semióticas: referemse ao estudo dos processos informacionais internos à comunicação, desde os mais simples - o modelo clássico: emissor/mensagem/meio/receptor - até aqueles que objetivam explicitar a produção semiótica do sistema de signos e significados que envolvem o processo de comunicação;

F novas demandas: referem-se a tendências de pesquisa que se desenvolvem a partir do entendimento que a mídia, em médio e longo prazos, altera o modo como as pessoas organizam sua percepção da realidade. Entre estas, são citadas:

\begin{abstract}
$\mathrm{G}$ a hipótese dos efeitos de longo prazo ou agenda-setting: aponta o papel da mídia no agendamento e hierarquização dos temas sociais sobre os quais se deve ter opinião, fornecendo-lhes também os principais elementos para a sua elaboração;

G a sociologia dos emissores ou newsmaking: centrado especialmente no campo da informação (notícias), sugere investigações para explicitar a lógica e os critérios do processo pelo qual os media responsáveis pela edição das informações selecionam e dão tratamento jornalístico às mesmas.
\end{abstract}


Já os chamados estudos culturais da corrente ou escola latinoamericana de comunicação interpelam o campo da mídia de massa a partir de outros pressupostos e, principalmente, de novas categorias de análise. Tendo em Jesus Martin-Barbero seu principal articulador - ao lado de Nestor Canclini, Guillermo Orozco e de brasileiros como Mauro Wilton de Souza e Renato Ortiz estes estudos propõem um voluntário afastamento em relação ao objeto da comunicação para tentar encontrar o caminho do movimento social da comunicação.

Em sua principal obra, De los Medios a las Mediaciones, MartinBarbero (1987) preconiza o afastamento tanto da noção de supremacia dos meios técnicos quanto de homogeneidade e passividade da audiência, que predominam nas pesquisas sobre mídia, optando pelo caminho das mediações como espaço cultural aberto à configuração/reconfiguração das mensagens midiáticas. Neste sentido, Jacks (1999) indica que

mediação pode ser entendida, portanto, como um conjunto de elementos que intervêm na estruturação, organização e reorganização da percepção da realidade em que está inserido o receptor, tendo poder também para valorizar implícita ou explicitamente esta realidade. As mediações produzem e reproduzem os significados sociais, sendo o "espaço" que possibilita compreender as interaçôes entre a produção e a recepção (p.48-49).

É justamente no campo dos estudos de recepção que reside a maior contribuição teórico-metodológica da escola latino-americana às pesquisas em comunicação de massa, ao ressaltar a importância de se investigar a diversidade de fatores culturais que, tanto no plano individual quanto coletivo, interferem na forma como os receptores percebem e atribuem sentido à mensagem. Na Educação Física brasileira, alguns estudos já vem se utilizando da dialética das múltiplas mediações para entender como receptores se relacionam com determinadas temáticas da área (Amaral,1999; Pires, Gonçalves e Padovani, 1999-a e 1999-b).

Outra sistematização importante para o estudo dos meios de comunicação de massa na sociedade contemporânea vem do inglês John B. Thompson, em obra na qual relaciona mídia, cultura e ideologia (Thompson, 1995). Como pressuposto conceitual, o autor propõe uma concepção estrutural de cultura, como o padrão de significados incorporados nas formas simbólicas, que inclui ações, manifestações verbais eobjetos significativos de vários tipos, em virtude dos quais os indivíduos comunicam-se entre si e partilham suas experiências, concepções e crenças (p.176), salientando que toda a significação e transmissão de formas simbólicas acontece em contextos e processos historicamente

Movimento, Porto Alegre, v. 9, n. 1, p. 09-22, janeiro/abril de 2003 
específicos e socialmente estruturados (p.181), os quais também devem ser objetivados na análise cultural para a interpretação dos significados das formas simbólicas. Para esta análise sobre a transmissão das formas simbólicas, que envolve a interpretação dos meios de comunicação de massa, Thompson recorre à hermenêutica de profundidade, com base em Paul Ricoeur, reconhecendo mas ao mesmo tempo propondo a superação da hermenêutica da vida cotidiana, para sugerir três passos ou fases de enfoque:

F análise sócio-histórica, cujo objetivo é reconstruir as condições sociais e históricas da produção, circulação e recepção das formas simbólicas;

$\mathrm{F}$ análise formal ou discursiva, envolvendo análises semiótica, de conversação, sintática, narrativa e argumentativa;

F interpretação/re-interpretação, que se refere à

"reconstrução criativa dos significados, isto é, uma explicação interpretativa do que está representado" (Thompson, 1995, p.375).

\section{Mídia e educação física no âmbito das Ciências do Esporte}

Depois dos estudos precursores na área, desenvolvidos por grupos e pesquisadores isolados em algumas instituições, o tema das relações entre mídia e Educação Física foi formalizado como um dos âmbitos de convergência no interior das Ciências do Esporte brasileiras. A partir da reformulação da instância científica do Colégio Brasileiro de Ciências do Esporte e da restruturação do seu principal evento, ocorrida a partir de 1997 (X CONBRACE Goiânia/GO), passaram a existir os Grupos de Trabalho Temáticos (GTT’s), com o objetivo de oxigenar as relações internas e externas da entidade científica. Foi neste contexto que a conexão Educação Física/Esporte, Comunicação e Mídia tornou-se temática interdisciplinar de estudos nas Ciências do Esporte, ${ }^{4}$ privilegiando, como afirmava a sua ementa, os estudos em Educação Física/ Ciências do Esporte relacionados aos interesses influências e possibilidades de interação deste campo de conhecimento/intervenção com as diferentes mídias e tecnologias comunicacionais (GTT3 - CONBRACE, 1997).

\footnotetext{
4 Coincidentemente, no mesmo período a INTERCOM - Sociedade Interdisciplinar de Estudos de Comunicação - criou o seu GT Esporte e Mídia, então sob a coordenação do Prof. Sérgio Carvalho (UFSM).
}

Movimento Porto Alegre, v. 9, n. 1, p. 09-22, janeiro/abril de 2003 
Naquele momento, a decisão da Diretoria Científica do CBCE, no que concerne à criação do GTT Educação Física/Esporte e Mídia, foi bastante prospectiva, pois o movimento que se percebia entre os pesquisadores da sociedade científica, nesta direção, era ainda bastante incipiente. Passados seis anos, o que se percebe é que, apesar de ainda não ter aumentado quantitativamente, os estudos apresentados têm se diversificado (e igualmente se aprofundado) quanto às bases conceituais e metodológicas utilizadas, demonstrando que, se não há tendências claramente identificáveis, existem todavia boas perspectivas de consolidação da área. Isso poderá vir a ocorrer principalmente porque, associadamente ao movimento ocorrido no interior do $\mathrm{CBCE}$, começam a surgir linhas de pesquisa nos Programas de Pós-Graduação em Educação Física que contemplam direta ou indiretamente a área.

Desde a primeira reunião do GTT, no CONBRACE de Goiânia (1997), existiu a preocupação de sistematizar a produção científica veiculada em categorias classificatórias, com a intenção de identificar tendências e lacunas. Naquele ano, assim como no CONBRACE seguinte (Florianópolis, 1999), somente as comunicações orais eram inscritas sob registro da área/GTT a que se destinavam. Desta maneira, desconsiderando os trabalhos inscritos/apresentados como pôster, teve-se a oportunidade de demonstrar quais as principais temáticas que compuseram o cenário do GTT no seu primeiro ano (Pires e Bittencourt, 1999), que foram distribuídos, então, em quatro grandes agrupamentos:

F estudos relacionados à área do marketing, envolvendo tanto o âmbito público quanto o privado;

F a área da mídia informativa de massa, referente à veiculação de temas da Educação Física/Ciências do Esporte, especialmente o esporte;

F o campo das chamadas novas tecnologias educacionais, que se refere ao uso pedagógico dos recursos da informática e da internet;

F estudos de reflexão teórica, marcadamente críticos à interação entre esporte e a mídia de massa na cultura contemporânea.

Feres Neto $(2000)^{5}$ também empreendeu esforço no sentido de sistematizar os trabalhos apresentados como comunicação oral

5 Este trabalho, de circulação restrita aos membros do GTT Esporte e Mídia, serviu também para estabelecer uma série de ações visando a consolidação do Grupo.

Movimento, Porto Alegre, v. 9, n. 1, p. 09-22, janeiro/abril de 2003 
no XI CONBRACE (1999), identificando tendências que modificavam pouco o contexto verificado no Congresso anterior.

A principal mudança verificada foi o desaparecimento de estudos relacionados ao marketing, estranhamente no exato momento em que, no campo do esporte profissional, esta área praticamente "explodia", com a crescente ampliação do chamado "negócio do esporte", em grande parte associado à indústria midiática (licenciamento, direitos televisivos, parcerias, etc.). Ao que parece, isso pode ser registrado como um exemplo da defasagem temporal que tende a existir entre os fatos sociais até a sua tomada como objeto de estudo do campo acadêmico-científico.

Outra nova característica observada por Feres Neto é quanto ao surgimento de estudos relativos à virtualização das práticas da cultura corporal, a partir do advento das novas tecnologias informacionais, já identificadas anteriormente mas aplicadas somente ao campo educacional.

\section{Nova tentativa de classificação dos estudos sobre mídia: o estado atual da arte?}

Diante das movimentações dos estudos sobre mídia no âmbito da Educação Física durante este curto período (1997-2001), que puderam ser observadas não só nas reuniões do GTT/CBCE, como também através de trabalhos apresentados em outros eventos científicos, nos periódicos da área, nos Programas de PósGraduação e como tema de monografias de conclusão de cursos de graduação e especialização em Educação Física, ficamos tentados a desenvolver um novo sistema classificatório, mais abrangente e explicativo, que ajude a organizar o entendimento sobre a produção acadêmica no campo da inter-relação Educação Física e Mídia. Como base teórica, tomamos por principal referência a síntese das principais teorias dos estudos de comunicação social, descritos no tópico 2 deste estudo.

Logicamente, como toda tentativa de sistematizar a produção de uma área, ela poderá ser contestado ou julgada inadequada. Todavia, seu objetivo já estará alcançado se estas críticas contribuírem para o aperfeiçoamento da proposta ou para o surgimento de outras, que possam facilitar a percepção dos pesquisadores interessados a este possível "estado atual da arte" na área, visando o seu desenvolvimento e consolidação.

Movimento Porto Alegre, v. 9, n. 1, p. 09-22, janeiro/abril de 2003 
A seguir, apresentamos o "desenho" desta sistematização e, logo adiante, os esclarecimentos necessários para a compreensão dos tópicos sugeridos, incluindo exemplos relativos aos trabalhos apresentados no XII CONBRACE (Caxambu, 2001), produzidos por Vieira et al. (2002). ${ }^{6}$

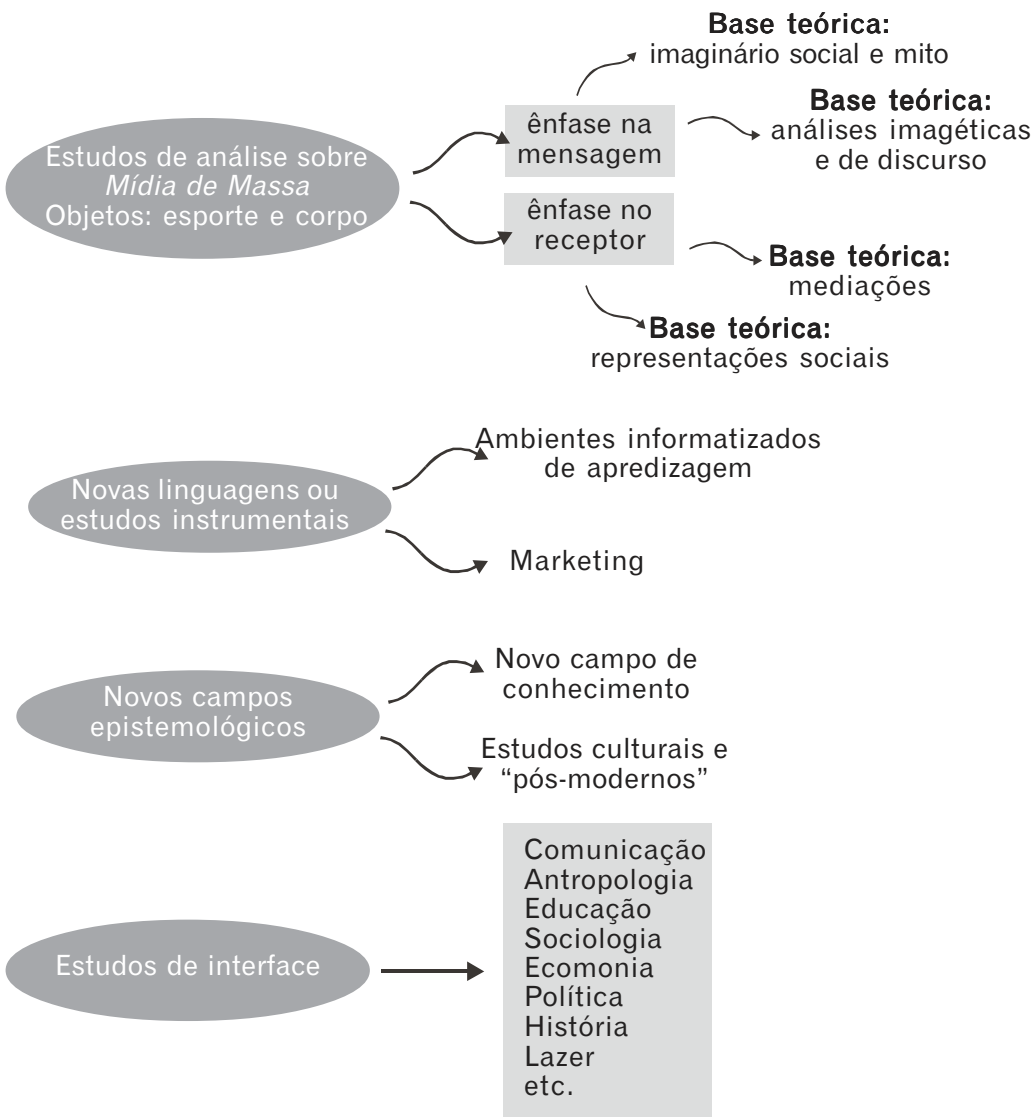

Figura 1 Sistematização dos estudos sobre mídia na educação física / ciências do esporte.

6 Os textos das comunicações orais e pôsteres inscritos no GTT 2 (esporte e mídia) que constam no CD-Rom dos Anais do XII CONBRACE/2001 foram analisados segundo este esquema, como exercício didático na disciplina Educação Física, Esporte e Mídia do curso de Educação Física/UFSC, por um grupo de acadêmicos (Vieira et al., 2002), aos quais agradeço sinceramente a autorização concedida para utilizar suas reflexões como exemplos neste texto.

Movimento, Porto Alegre, v. 9, n. 1, p. 09-22, janeiro/abril de 2003 
Examinando-se a produção sobre mídia no âmbito da Educação Física, a partir do esquema proposto, pode-se perceber que o principal foco dos estudos, ao menos quantitativamente, está centrado na análise de como os meios de comunicação de massa se apropriam e veiculam temas da área, especialmente aqueles que têm como principal objeto a produção/veiculação do esporte telespetáculo (Betti, 1998) ou a construção da imagem social de corpo.

Duas são as principais ênfases identificadas entre estes estudos:

G os que centram suas análises na própria mensagem veiculada pelos meios e

G aqueles que preferem examinar como os receptores percebem e atribuem significados a ela.

Nos primeiros - centrados na mensagem -, as principais bases teóricas utilizadas são relativas ao exame da produção do imaginário social e do mito do herói no esporte, e aos estudos que promovem análises semióticas e/ou de discurso sobre imagens/textos relacionados à construção do discurso midiático sobre esporte ou corpo. Este parece ser o caso do texto de Bohrer et al., Mídia impressa e Copa Davis no Brasil: descrição e comentários.

Já os estudos de recepção têm como principais quadros de referência o conceito de mediações e a teoria das representações sociais, compreendendo, entre os primeiros, aqueles que examinam como se dá o processo de atribuição de sentidos à mensagem midiática e, entre os últimos, a análise das formas como estes significados são individual e socialmente manifesto pelos receptores. Neste último grupo, Vieira et al.(2002) identificaram o trabalho O campo Esportivo e a Mídia: a Educação Física em Silêncio (Bittencourt).

O segundo agrupamento de trabalhos apontado nesta sistematização tem caráter mais instrumental, isto é, percebem e operam os meios tecnológicos de informação como facilitadores do acesso e apropriação de conteúdos temáticos específicos. Entre estes, destacam-se as propostas comunicacionais que preconizam a utilização das novas linguagens midiáticas para o desenvolvimento de ambientes informatizados de aprendizagem ou como estratégia para a veiculação de material de marketing promocional ou institucional. Dentro da primeira perspectiva, encontramos estudos como o de Nista-Piccolo e Zilberberger - Mundo da (In)formação sobre a Cultura Corporal: ... - e o de Silva - Análise de conformidade ergonômica de programas informatizados para a Educação Física.

Movimento Porto Alegre, v. 9, n. 1, p. 09-22, janeiro/abril de 2003 
Com algumas sutis mas importantes diferenças em relação aos anteriores, destacam-se os estudos que pensam as oportunidades viabilizadas pela mídia, especialmente a informatizada, como novos campos epistemológicos para a Educação Física. Para estes, mais do que uma nova linguagem, o mundo digital e em rede configura-se como um amplo espaço comunicacional virtual, com influência não apenas na transmissão mas sobretudo na produção de novos conhecimentos para a cultura de movimento, o esporte, o lazer, etc. O entusiasmo com estas possibilidades vai da proposição do surgimento de um campo de conhecimento e profissional próprio, resultante da interação entre Educação Física e Jornalismo, até os estudos culturalistas, aqui denominados "pós-modernos", por identificarem, em determinadas práticas corporais associadas a novas ferramentas da mídia, a presença de elementos de uma cultura pós-estruturalista, como parece ser o caso do trabalho Hip-Hop: tatuagens urbanas de uma cultura ordinária, de Rotta et al.

O último grupo de trabalhos que se pode observar são os que promovem interfaces de outras ciências - como a História, a Sociologia, a Economia, a Medicina, etc. - com a Educação Física. A partir de referências conceituais e metodológicas destas outras áreas do conhecimento, tomam por objeto de estudo determinados conteúdos que integram o campo da Educação Física - especialmente os relativos a corpo e esporte. Referimo-nos aqui aos que interessam aos objetivos deste texto, isto é, aqueles que expressam relações, ainda que tangenciais, com a mídia. Neste grupo, foi possível identificar, por exemplo, o trabalho de Gastaldo, Corpo, Propaganda e Imaginário Social.

Vale salientar que muitos destes estudos sequer são veiculados em periódicos ou eventos das Ciências do Esporte, encontrando guarida nas suas próprias sociedades científicas. A respeito deles, urge que a Educação Física estabeleça canais efetivos de diálogo, que possibilitem a ampliação da base teórica do nosso campo de conhecimento.

Para concluir, destacamos que, à medida que os trabalhos de abordagem teórica crítico-reflexiva sobre as relações entre mídia e as diferentes manifestações da Educação Física vão se ampliando, diversificando e aprofundando, mais visível se torna a ausência e ainda mais necessária se faz a produção de estudos que formulem e experimentem propostas metodológicas de trato pedagógico sobre o tema destas relações no âmbito do siste-

Movimento, Porto Alegre, v. 9, n. 1, p. 09-22, janeiro/abril de 2003 
ma educacional, nas aulas de Educação Física escolar. Esta é uma condição indispensável para que possamos examinar as possibilidades e os limites reais de se compreender este componente curricular como um espaço didaticamente adequado para buscar a formação de receptores mais esclarecidos, críticos e seletivos. Um dos poucos estudos nesta direção, daqueles apresentado no XII CONBRACE, é o trabalho de Betti (Imagem e ação: a televisão e a Educação Física Escolar - resultados iniciais).

\section{Considerações finais}

A intenção manifesta de tentar traçar cenário que explicite um possível estado atual da pesquisa em Educação Física/Ciências do Esporte relacionada aos meios comunicacionais e de informação de massa, que perpassa o presente texto, visou sobretudo oferecer melhores condições de acesso e compreensão de novos pesquisadores ao percurso deste campo temático interdisciplinar.

Quanto à opção por centrar as análises nos trabalhos apresentados no GTT Esporte e Mídia do Colégio Brasileiro de Ciências do Esporte, ainda que não exclusivamente, mais que tudo significa o reconhecimento daquela instância científica como o principal espaço para a veiculação, o debate e a produção coletiva de novas possibilidades de investigação no campo da Educação Física, tendo em conta sua interação com a mídia.

Neste sentido, o já referido surgimento de linhas de pesquisa nos Programas de Pós-Graduação, com pesquisadores que têm atuado também na graduação, é notícia bastante alvissareira, pois o aumento da quantidade e o aprofundamento qualitativo dos estudos produzidos no âmbito acadêmico podem contribuir significativamente para a consolidação da área temática, dentro e para além do próprio GTT do CBCE.

Movimento Porto Alegre, v. 9, n. 1, p. 09-22, janeiro/abril de 2003 
Research in physical education and the media in the science of sport: a possible current state of the art

Abstract: from some reflections on the relations between contemporary culture, the means of mass communication and the field of knowledge Physical Education, is formulated a brief classificatory synthesis of the studies on this area of interface, presented within the scope of GTT Sport and Media of the Brazilian College of Sport Science (1997/2001), with the aim of illustrating the possible current state of the art.

Keywords: Physical Education, Sport, Media.

\begin{abstract}
La investigación en educación fisica y midia en las ciencias del deporte: un posible estado actual del arte Resumen: partiendo de algunas reflexiones sobre las relaciones entre la cultura contemporanea, los medios de comunicación de masa y el campo de Educación Física, se formula una breve sintesis clasificatoria de los estudios en este area de interfase, presentados en el ámbito del GTT Deporte y Midia del Colegio Brasileño de Ciencias del Deporte (1997-2001), como ilustración de un posible estado actual del arte.
\end{abstract}

Palabras claves: Educación fisica, Deporte, Midia.

\title{
Referências
}

AMARAL, Silvia Cristina Franco. Estudo descritivo sobre a relação entre as mensagens televisivas e o discurso de praticantes - o papel das mediações. Revista Brasileira de Ciências do Esporte, v.21, n.1, p. 401-406, set., 1999.

BETI, Mauro. A janela de vidro. Campinas: Papirus, 1998.

FERES Neto, Alfredo. Sistematização da produção veiculada em 1997/1999, algumas implicações político-pedagógicas e agenda de trabalho para o período 1999/2001. GTT Éducação Física/Esporte, Comunicação e Mídia/CBCE, 2000 (não publicado).

FERES Neto, Alfredo. A virtualização do esporte e suas novas vivências eletrônicas (Resultados Finais). In: Congresso Brasileiro de Ciências do Esporte, 12, Anais... . Caxambu: 2001 (CD-Rom).

JACKS, Nilda. Querência: cultura regional como mediação simbólica - um estudo de recepção. Porto Alegre: Ed. Universidade/UFRGS, 1999.

MARTIN-BARBERO, Jesus. De los medios a las mediaciones. México: GG, 1987.

PIRES, Giovani de Lorenzi. Educação Física e o discurso midiático: abordagem crítico-emancipatória. Ijuí: Ed. UNIJUí, 2002.

Movimento, Porto Alegre, v. 9, n. 1, p. 09-22, janeiro/abril de 2003 
PIRES, Giovani de Lorenzi; GonÇALVES, Aguinaldo; PADOVANI, Carlos Roberto. Recepção à mídia esportiva entre acadêmicos de educação física da UFSC: estudo sobre opiniões conforme posição na estrutura curricular. Revista Brasileira de Ciências do Esporte, v. 21, n. 1, p. 388-394, set., 1999-a.

PIRES, Giovani de Lorenzi; GONÇALVES, Aguinaldo; PADOVANI, Carlos Roberto. Estudo sobre a mediação institucional formação profissional na recepção à mídia esportiva entre acadêmicos da UFSC. Reunião Anual da SBPC, 51, Anais... . Porto Alegre: 1999-b (CD-Rom).

PIRES, Giovani L.; BITTENCOURT, Fernando Gonçalves. Comunicação e mídia no âmbito do conhecimento e intervenção em educação física/ciências do esporte. In: GOELLNER, Silvana (org.). Educação Física/Ciências do Esporte: Intervenção e Conhecimento. Florianópolis: Colégio Brasileiro de Ciência do Esporte, 1999.

THOMPSON, John B. Ideologia e cultura moderna. Petrópolis: Vozes, 1995.

VIEIRA, Carmen Lúcia et al. Categorização dos Trabalhos apresentados no GTT Educação Física, Esporte, Comunicação e Mídia do XII CONBRACE/2001. Florianópolis: Curso de Educação Física/UFSC, 2002 (não publicado).

WOLF, Mauro. Teorias da comunicação, 6.ed. Lisboa: Presença, 2001.

Obs.: os textos citados no tópico 4, todos referenciados em Vieira et al. (2002), podem ser encontrados nos Anais em CD-Rom do XII CONBRACE (2001). 